\title{
Macrophage IFN-I signaling promotes autoreactive $T$ cell infiltration into islets in type 1 diabetes model
}

\author{
Brett S. Marro, Sarah Legrain, Brian C. Ware, and Michael B.A. Oldstone \\ Viral-Immunobiology Laboratory, Department of Immunology \& Microbiology, The Scripps Research Institute, La Jolla, \\ California, USA.
}

\begin{abstract}
Here, we report a pathogenic role for type I IFN (IFN-I) signaling in macrophages, and not $\beta$ cells in the islets, for the development of type 1 diabetes (T1D). Following lymphocytic choriomeningitis (LCMV) infection in the Rip-LCMV-CP T1D model, macrophages accumulated near islets and in close contact to islet-infiltrating GP-specific (autoimmune) CD8+ $\mathrm{T}$ cells. Depletion of macrophages with clodronate liposomes or genetic ablation of Ifnar in macrophages aborted T1D, despite proliferation of GP-specific (autoimmune) CD8 ${ }^{+} \mathrm{T}$ cells. Histopathologically, disrupted IFN $\alpha / \beta$ receptor (IFNAR) signaling in macrophages resulted in restriction of $C D 8^{+} \mathrm{T}$ cells entering into the islets with significant lymphoid accumulation around the islet. Collectively, these results provide evidence that macrophages via IFN-I signaling, while not entering the islets, are directly involved in interacting, directing, or restricting trafficking of autoreactive-specific $\mathrm{T}$ cells into the islets as an important component in causing T1D.
\end{abstract}

Conflict of interest: The authors have declared that no conflict of interest exists.

License: Copyright 2019, American Society for Clinical Investigation.

Submitted: September 24, 2018 Accepted: December 11, 2018 Published: January 24, 2019

\section{Reference information:} JCI Insight. 2019;4(2):e125067. https://doi.org/10.1172/jici. insight.125067.

\section{Introduction}

Type 1 diabetes (T1D) is an autoimmune disorder defined by the progressive and irreversible destruction of insulin-producing $\beta$ cells within the islets of Langerhans of the pancreas. By the time of clinical diagnosis, autoimmune T cells causing T1D will have eliminated a majority of $\beta$ cells, resulting in hypoinsulinemia and a rise in blood glucose (BG) levels. Ketoacidosis and death will ultimately occur, unless exogenous insulin therapy is provided. Nevertheless, daily insulin therapy does not prevent complications of stroke, heart disease, visual impairment, or faulty wound healing, indicating the need to preserve $\beta$ cells in the prediabetic stage to ensure endogenous insulin production. A seminal question in the pathogenesis of T1D is what deleterious signals activate autoreactive lymphocytes and/or control their entry into islets prior to engaging and killing insulin-producing $\beta$ cells.

Type I IFN (IFN-I) are pleiotropic cytokines that induce potent antiviral programs to protect the host from microbial infections, but they also potentiate the diabetogenic process of $\beta$ cell destruction (1-10). Our recent study (8) and that of Carrero et al. (11) have documented distinctive IFN-I gene signatures in islets that precede lymphocytic infiltration into the islets in 2 distinctly different experimental models of T1D. Moreover, expression of IFN-I-inducible genes in peripheral blood mononuclear cell (PBMC) samples isolated from children at risk for T1D preceded onset of autoimmunity and seroconversion in 2 independent longitudinal studies $(12,13)$. Importantly, a link between the IFN- $\alpha$ species $-1,-2,-5,-8$, and -14 and T1D was discovered in humans susceptible to developing T1D due to mutations in autoimmune regulator (AIRE) (14) and IFN- $\alpha$ species $-1,-4,-5,-11$, and -13 in our experimental mouse model (8). For that model, mice are genetically engineered to express the lymphocytic choriomeningitis (LCMV) glycoprotein (GP) from the rat insulin promoter (Rip-GP). When challenged with LCMV or a virus with cross-reactive GP-specific T cells, T1D occurs (15-17). Neutralization of 2 of the IFN- $\alpha$ species in humans and mice were similar (IFN- $\alpha 1$, IFN- $\alpha 5$ ), strongly suggesting that expression of selected IFN-I species prior to fulminant T1D disease was both a marker and critical mediator of $\beta$ cell destruction in both human and our Rip-GP mouse model.

Although IFN-I are considered a key autoinflammatory component within islet lesions, the cell subsets targeted by IFN-I that influence T1D disease are less understood. One major effect of IFN-I is the upregulation of MHC-I $(18,19)$, as culturing human $\beta$ cells in the presence of IFN-I induces MHC-I expression 
(20), while in vivo MHC-I hyperexpression is a principle feature of the inflamed islet during clinical T1D $(19,21)$. These results suggest that IFN-I may have an important role in inducing islet-antigen expression on $\beta$ cells, an event that we study and address in this paper.

A second possible cellular target of IFN-I is the tissue-resident macrophage. Three populations of macrophages have been described to reside within the pancreas and all share the expression of the canonical macrophage marker F4/80 (22). Several studies in NOD mice have described a pathogenic role for macrophages (23-27). Most notable were 2 recent studies by Emil Unanue's group $(24,28)$, who showed that islet-resident macrophages are in a persistent inflammatory state prior to signs of $\beta$ cell pathology and that their depletion significantly reduced diabetes. However, it is not currently known if IFN $\alpha / \beta$ receptor (IFNAR) signaling in macrophages serves a pathogenic role in the context of T1D; this is the second event we address in this paper.

Using Cre-inducible-KO mice to ablate Ifnar in defined cellular subsets, we find that, while elimination of IFN-I signaling on $\beta$ cells does not interfere with the progression of T1D, ablation of IFN-I signaling on macrophages does significantly limit the onset of T1D.

\section{Results}

T1D disease progression In Rip-GP mice is not dependent on IFNAR signaling in $\beta$ cells of the islets. Infection of Rip-GP mice with LCMV results in the development of T1D between 10 and 15 days after infection (p.i.) due to the selective killing of $\beta$ cells by LCMV GP-specific cytotoxic T cells (CTLs) that recognize the viral GP transgene expressed solely by pancreatic $\beta$ cells $(8,15,16)$. Using Rip-GP mice, we previously identified IFN- $\alpha$, but not IFN- $\beta$, as a pathogenic factor required to promote the infiltration of GP-specific (autoimmune) $\mathrm{CD}^{+} \mathrm{T}$ cells into the islets, where they target and kill insulin-producing $\beta$ cells (8). To determine if IFN-I signaling in $\beta$ cells in the islets is required for T1D development in Rip-GP mice, the IFN-I receptor (Ifnar) was genetically deleted in $\beta$ cells by crossing Rip-GP mice to Ins1-Cre ${ }^{+/-}$Ifnar ${ }^{\mathrm{fl} / \mathrm{fl}}$ mice. $\beta$ Cell-specific loss of Ifnar was confirmed by culturing islets from Rip-GP ${ }^{+/-}$Ins1-Cre ${ }^{+/-}$Ifnar $^{\mathrm{f} / \mathrm{fl}}$ (designated Rip-Ins1-Ifnar $\left.{ }^{\mathrm{t} / \mathrm{fl}}\right)$ and Rip-GP ${ }^{+/-}$Ins1-Cre ${ }^{+/-}$Ifnar $^{\mathrm{wt} / \mathrm{wt}}\left(\right.$ Rip-Ins1-Ifnar $\left.^{\mathrm{wt} / \mathrm{wt}}\right)$ mice for 12 hours in the presence of $100 \mathrm{U} / \mathrm{ml}$ IFN- $\beta$ or vehicle control. A significant reduction in the mRNA transcript level of several IFN-stimulated genes, including IFN- $\alpha, M x 1$, Ifit1, Stat1, and Oasl2, was noted in islets isolated from Rip-Ins1-Ifnar ${ }^{\mathrm{f} / \mathrm{fl}}$ mice compared with islets from Rip-Ins1-Ifnar ${ }^{\mathrm{wt} / \mathrm{wt}}$ mice, indicating that the IFNAR signaling axis was disrupted in $\beta$ cells of Rip-Ins1-Ifnar ${ }^{\mathrm{f} / \mathrm{fl}}$ mice (Figure 1A). Thereafter, Rip-Ins1-Ifnar ${ }^{\mathrm{f} / \mathrm{fl}}$ and Rip-Ins1-Ifnar ${ }^{\mathrm{wt} / \mathrm{wt}}$ mice were infected by i.p. injection of the clone 13 (Cl13) variant of LCMV-Arm53b and BG levels monitored. We found the average BG level to be significantly lower at day 10 p.i. and day 15 p.i. in Rip-Ins1-Ifnar ${ }^{\mathrm{A} / \mathrm{fl}}$ mice, although 10/11 Rip-Ins1-Ifnar ${ }^{\mathrm{f} / \mathrm{fl}}$ mice had clinical T1D disease (BG $\left.>250 \mathrm{mg} / \mathrm{dl}\right)$ by day 15 p.i. (Figure 1B). Furthermore, lymphoid accumulation within the islets of Rip-Ins1-Ifnar ${ }^{\mathrm{fl} / \mathrm{ll}}$ mice was comparable with controls at day 15 p.i. (Figure 1C). These results indicate that IFN-I signaling in $\beta$ cells in the islets of Rip-GP mice has a small role in promoting islet destruction and development of T1D.

Myeloid lineage cells are required for T1D disease development. Macrophages are an IFN-I-responsive population of myeloid cells implicated in promoting T1D disease $(27,28)$. Using flow cytometry and immunofluorescence (IF) analysis, we detected a significant increase in $\mathrm{F} 4 / 80^{+}$macrophages infiltrating into the pancreata at day 5 p.i. compared with naive controls following infection with LCMV-C113 (Figure 1D). Many of these macrophages were localized at the islet capsule and closely associated with GP-specific $\mathrm{CD}^{+} \mathrm{T}$ cells expressing the congenic marker CD90.1 (Supplemental Figure 1; supplemental material available online with this article; https://doi.org/10.1172/jci.insight.125067DS1). To determine if GP-specific $\mathrm{CD}^{+} \mathrm{T}$ cell-mediated recruitment of macrophages was responsible for this increase in macrophage number at day 5 p.i., Rip-GP mice were infected with the glycoprotein variant (GPV) of LCMV. The LCMV GPV contains mutations in the GP $\left(\mathrm{GP}_{33-41}[\mathrm{GP} 38\right.$ phenylalanine to leucine $(\mathrm{F} / \mathrm{L})]$ and $\mathrm{GP}_{276-286}[\mathrm{GP} 282$ glycine to aspartic acid (G/D)]), thereby limiting the expansion of GP-specific $\mathrm{CD} 8^{+} \mathrm{T}$ cells that target $\beta$ cells presenting the 2 immunodominant $\mathrm{H} 2-\mathrm{D}^{\mathrm{b}}$ restricted $\mathrm{GP}_{33-41}$ and $\mathrm{GP}_{276-286}$ peptides. Infection of RipGP mice with LCMV-GPV resulted in a statistically significant increase in the frequency of macrophages infiltrating in the pancreata at day 5 p.i., indicating that macrophages are directed into the pancreata independently of LCMV-GP ${ }_{33-41}$ - and $\mathrm{GP}_{276-286}$-specific CTLs in the islets (Figure 1D). To determine if macrophages are required to induce T1D disease in Rip-GP mice, we first depleted macrophages with clodronate encapsulated liposomes. Administration of clodronate liposomes by i.v. route results in rapid depletion of macrophages, whereas i.p. administration accounts for a slower but longer depletion (29). Within the 
A

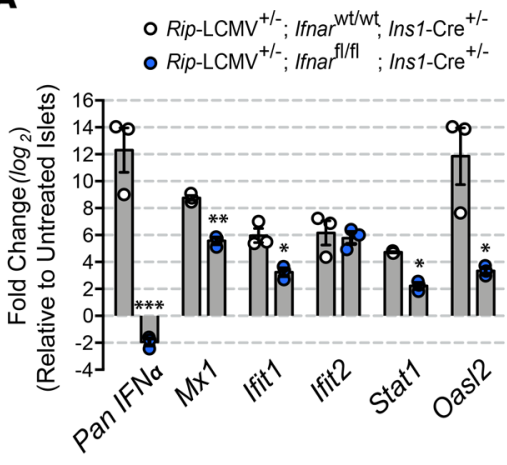

C

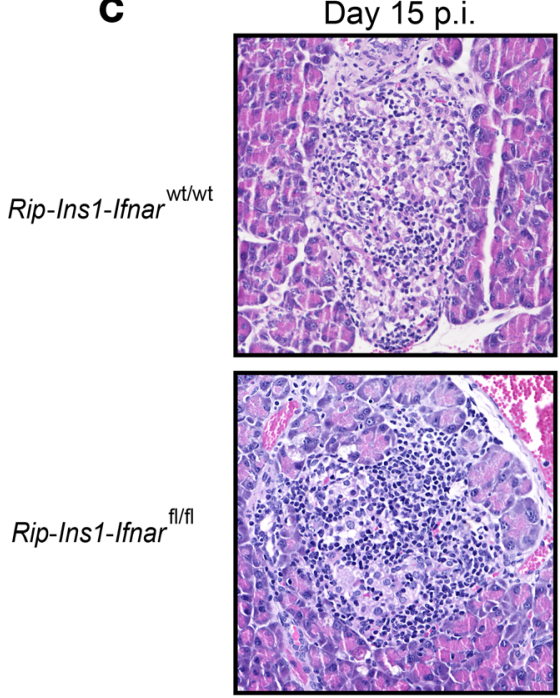

B

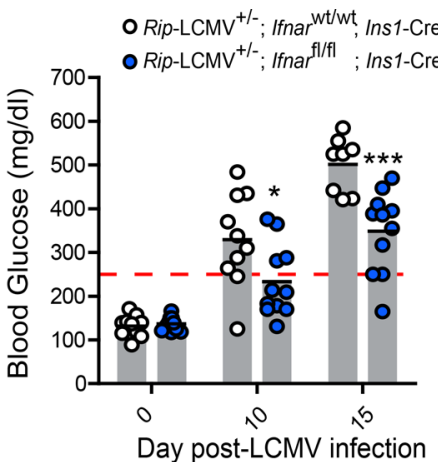

D

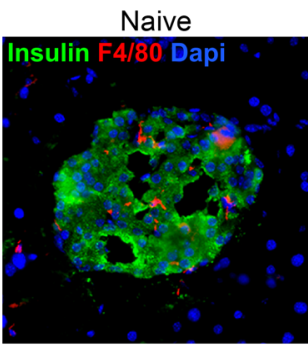

Naive

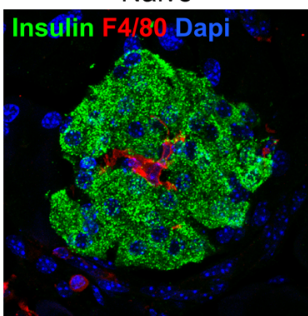

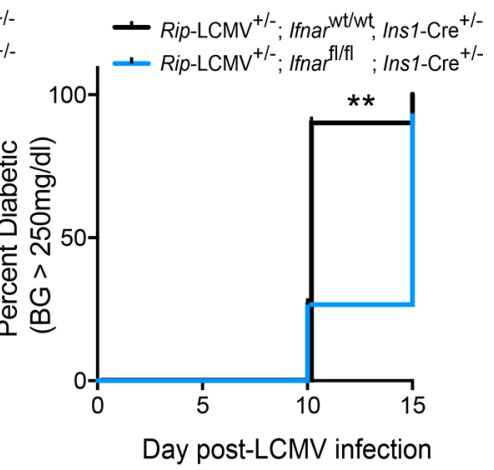

Day post-LCMV infection
E
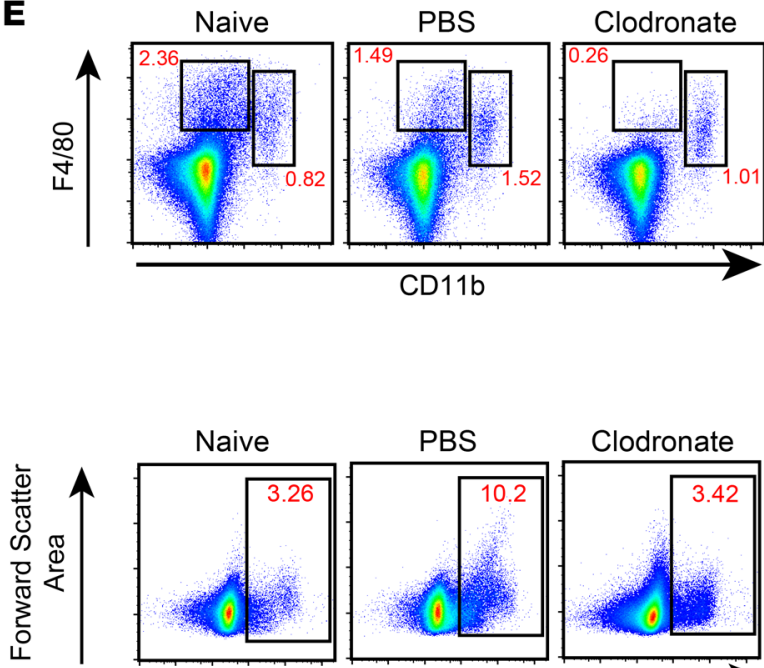

PBS

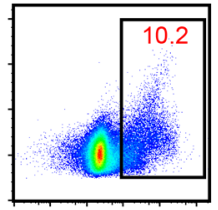

CD11b

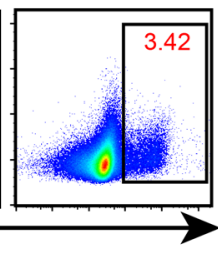

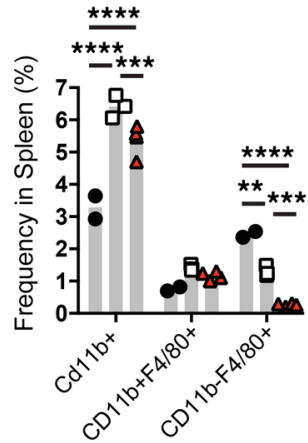

- Naive

- PBS Liposome

$\triangle$ Elodronate Liposome
LCMV-GPV

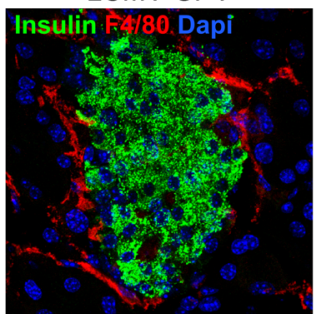

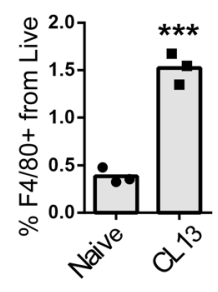

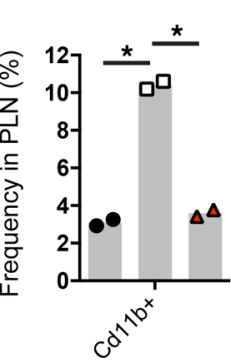

- Naive

- PBS Liposome

$\triangle$ Clodronate Liposome

Figure 1. Expression of IFNAR in insulin-producing $\beta$ cells has a minor role in the development of T1D. (A) qPCR analysis of IFN $\alpha$, Mx1, Ifit1, Ifit2, Stat1, and Oas/2 mRNA expression in pancreatic islets isolated from Rip-Ins1-Ifnar ${ }^{f / / f l}$ and Rip-Ins1-Ifnar ${ }^{\mathrm{ft} / \mathrm{wt}}$ mice. Islets were cultured in the presence of IFN- $\beta$ $(100 \mathrm{U} / \mathrm{ml})$ for 12 hours prior to RNA extraction. (B) Blood glucose levels and T1D incidence over a 15-day postinfection period. (C) Representative H\&E images (20x magnification) of the pancreatic islets from Rip-Ins1-Ifnar ${ }^{\mathrm{fl} / \mathrm{fl}}$ and Rip-Ins1-Ifnar fl/wt mice at day 15 p.i. (D) Pancreata were isolated at day 5 p.i. from Rip-GP mice infected i.p. with $2 \times 10^{5}$ PFU LCMV or $2 \times 10^{5}$ LCMV-GPV. Half pancreata was stained via immunofluorescence with antibody to insulin and $\mathrm{F} 4 / 80$ (40x magnification). Macrophages were examined in the second half of pancreatic tissue by flow cytometry by gating on CD45 ${ }^{+} 4 / 80^{+}$ cells. (E) Frequency of CD11b+ cells in the spleens and PLNs of clodronate liposome-treated mice at day 3 after LCMV infection. qPCR analysis was 
performed on RNA isolated from islets of 3 mice per group. Fold change in gene expression was relative to islets treated with vehicle control (PBS). Data are presented as average \pm SEM; statistical significance was measured using an unpaired 2-tailed Student $t$ test or 1-way ANOVA analysis. Statistical significant of T1D disease incidence was measured using a log-rank (Mantel-Cox) test. ${ }^{*} P<0.05,{ }^{* *} P<0.01,{ }^{* * *} P<0.001,{ }^{* * * *} P<0.0001$.

context of experimental LCMV infection, clodronate liposomes were previously shown to selectively target and deplete red pulp macrophages (RPM), marginal zone macrophages (MZM), metallophilic macrophages (MZM), and likely a small fraction of immature DCs (30). Rip-GP mice received clodronate liposomes by i.v. injection 8 hours prior to LCMV infection and by i.p. injection 24 hours after infection. At day 3 p.i., a significant reduction in cells expressing the surface phenotype CD $11 b^{-} \mathrm{F} 4 / 80^{+}$, which is characteristic of RPM, was found in the spleens of clodronate treated mice, while the total CD $11 b^{+}$cell population in the spleens and pancreatic lymph nodes (PLNs) of clodronate-treated animals was significantly lower than PBS liposome-treated controls (Figure 1E). Mice depleted of $\mathrm{F} 4 / 80^{+}$cells were resistant to developing T1D (BG $<250 \mathrm{mg} / \mathrm{dl})$ to the day-54 post-LCMV infection observation period, while all PBS liposome-treated Rip-GP control animals developed disease (BG $>250 \mathrm{mg} / \mathrm{dl}$ ) by day 14 p.i. (Figure 2A). To track GP33-specific (autoimmune) T cells that target and lyse GP-expressing $\beta$ cells, 20,000 TCR transgenic P14 CD8 ${ }^{+} \mathrm{T}$ cells recognizing the LCMV-GP ${ }_{33-41}$ epitope were adoptively transferred into Rip-GP mice prior to clodronate liposome treatment. $\mathrm{P} 14 \mathrm{CD} 8^{+} \mathrm{T}$ cells were rarely detected near or within islets of clodronate-treated mice, as opposed to control animals, which showed significant peri-islet accumulation and infiltration of $\mathrm{P} 14 \mathrm{CD}^{+} \mathrm{T}$ cells into the islets (Figure 2B). We also noted a majority of P14 $\mathrm{T}$ cells in close contact with $\mathrm{F} 4 / 80^{+}$macrophages in and around the islets at day 7 p.i. (Figure $2 \mathrm{~B}$ and Supplemental Figure 1). The lack of infiltration of GP-specific $\mathrm{CD} 8^{+} \mathrm{T}$ cells into the pancreata of clodronate-treated mice was not the result of a lack of expansion of these cells, since the frequency of TCR transgenic P14 CD8 ${ }^{+}$ $\mathrm{T}$ cells in the spleens were comparable with PBS controls; however, in the PLNs, there was a significant increase in the frequency of P14 T cells in clodronate-treated mice at day 6 after LCMV infection (Figure 2C). In other experiments, clodronate-treated animals showed a decrease in the frequency of endogenous $\mathrm{GP}_{33-41}$-specific $\mathrm{CD}^{+} \mathrm{T}$ cells and also $\mathrm{CD}^{+} \mathrm{T}$ cells specific to the immunodominant $\mathrm{NP}_{396-404}$ epitope, indicating some alterations in LCMV-specific T cell expansion when P14 T cells are not adoptively transferred into Rip-GP mice prior to infection (Figure 2D). Administration of clodronate liposomes resulted in poor control of viremia to day 53 p.i. (Figure 2E). Additionally, LCMV-C113 was detected in a majority of islets and throughout the exocrine compartment of the pancreata at day 15 p.i., while virus was restricted to inside the islets at day 53 p.i. in clodronate-treated Rip-GP mice (Figure 2F). Collectively, these results highlight a dichotomous role for macrophages during acute LCMV infection in Rip-GP mice. As expected, macrophages are required to prevent early LCMV dissemination, but unexpectedly, they promoted autoaggressive $\mathrm{CD}^{+} \mathrm{T}$ cell infiltration into the pancreatic islets to cause T1D.

Genetic deletion of Ifnar from macrophages spares mice from $L C M V$-induced T1D disease. To determine if IFN-I signaling in macrophages is required for T1D disease, Rip-GP mice were crossed to LysM-Cre ${ }^{+/-}$Ifnar $^{\text {fl/fl }}$ mice to generate Rip-LysM-Ifnar ${ }^{\mathrm{f} / \mathrm{fl}}$ or Rip-LysM-Ifnar ${ }^{\mathrm{f} / \mathrm{wt}}$ control mice. Lysozyme M (LysM), which is encoded by the $L y z 2$ gene, is predominantly expressed in myeloid lineage cells, including monocytes, macrophages, and neutrophils (31), and LysM-Ifnar ${ }^{\mathrm{I} / \mathrm{l}}$ mice show selective elimination of Ifnar in myeloid lineage cells and not DCs, NK cells, or lymphocytes (32-34). In agreement with these studies, there was a substantial decrease in IFNAR surface expression on splenic macrophages from $L y s M$-Ifnar ${ }^{\mathrm{f} / \mathrm{fl}}$ mice, but no difference was found in the expression level of IFNAR on DC or T cells compared with Ifnar ${ }^{\mathrm{f} / \mathrm{fl}}$ control mice (Figure 3A).

Elimination of Ifnar in myeloid cells prevented the development of T1D disease until at least 30 days after LCMV infection, while 7 of 8 mice with at least 1 functional Ifnar allele developed disease by day 10 p.i. (Figure 3B). Histopathological analysis of pancreas tissue from Rip-LysM-Ifnar ${ }^{\mathrm{l} / \mathrm{ll}}$ mice revealed the presence of lymphoid cells at the peri-islet walls and an overall lack of lymphoid cells infiltrating into the islets at day 11 p.i. (Figure 3C). By day 30 p.i., significant pancreatic injury was observed within the exocrine compartment of Rip-LysM-Ifnar ${ }^{\mathrm{f} / \mathrm{fl}}$ mice, including the presence of inflammatory cells in the acinus and around islets and signs of acinar cell loss (Figure 3C). Of the 8 Rip-LysM-Ifnar ${ }^{\mathrm{fl} / \mathrm{wt}}$ mice infected with LCMV-Cl13, 1 mouse having BG levels below $250 \mathrm{mg} / \mathrm{dl}$ at day 30 p.i. still showed islet destruction and presence of lymphoid cells in islets, indicating an ongoing loss of $\beta$ cells (Figure 3C). Pancreatic islets within Rip-LysM-Ifnar ${ }^{\mathrm{f} / \mathrm{wt}}$ mice displayed robust P14 CD8 ${ }^{+} \mathrm{T}$ cell infiltration at 10 p.i. In contrast, $\mathrm{P} 14 \mathrm{~T}$ cells in virus-infected Rip-LysM-Ifnar ${ }^{\mathrm{f} / \mathrm{fl}}$ mice were mainly localized at peri-islet areas and not within the islets (Figure 3D). Furthermore, we did not detect significant differences in the frequency of P14 T cells in the 
A

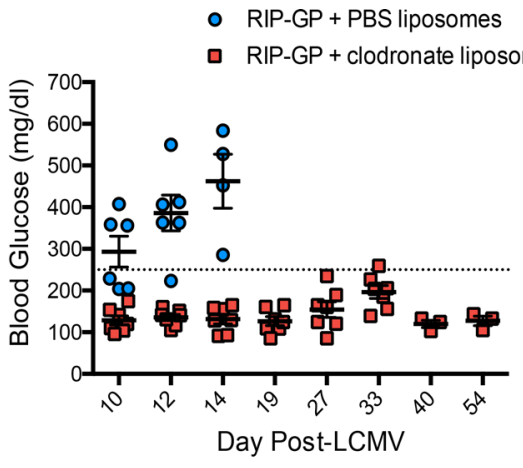

B
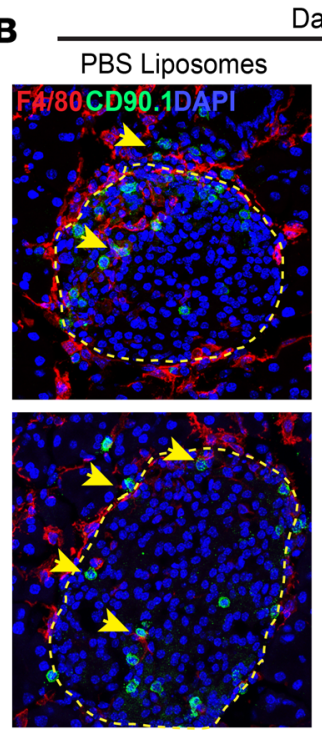

Day 7

Clodronate Liposomes
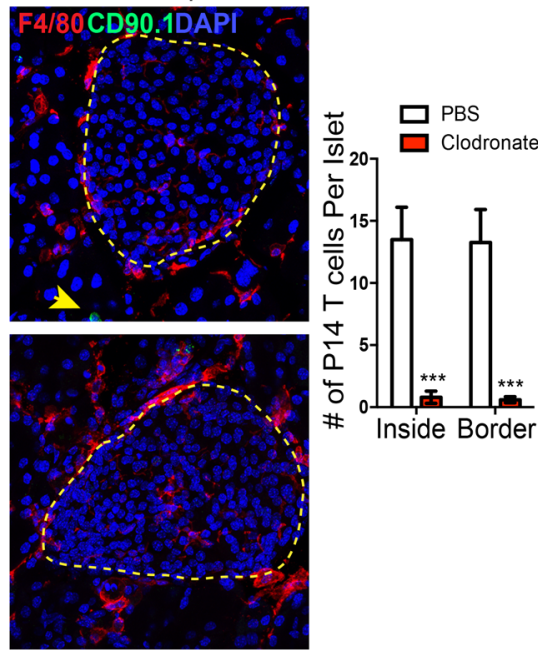

c

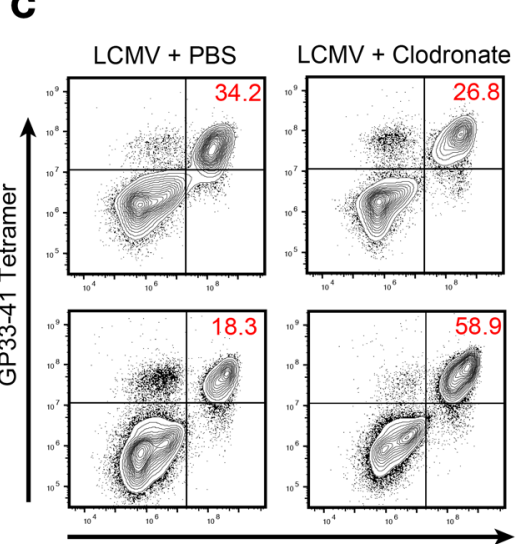

CD90.1

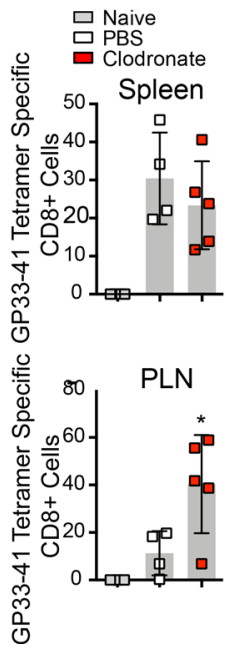

D

PBS Liposomes Clodronate Liposomes
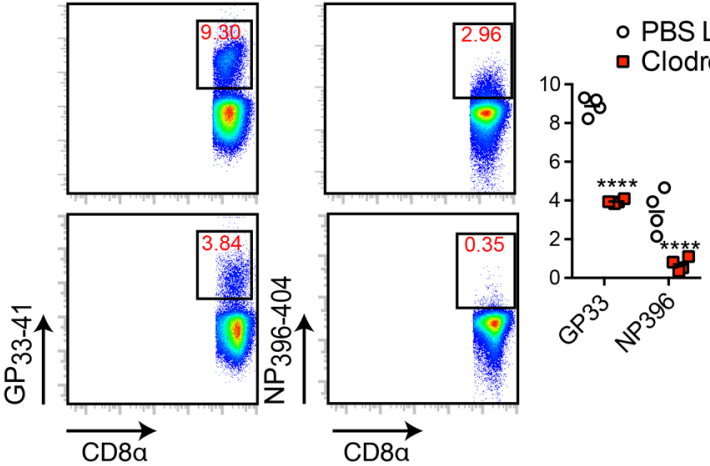

$\mathbf{E}$
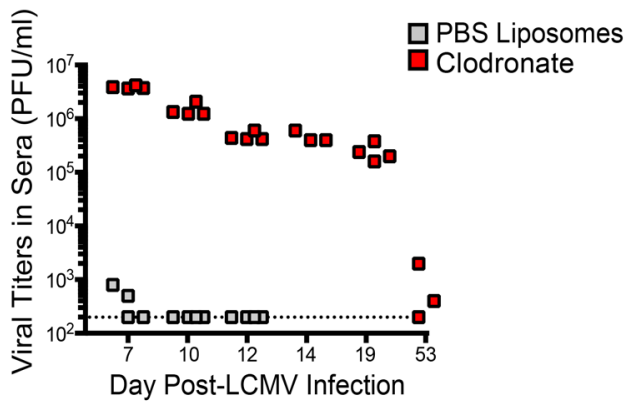

$\mathbf{F}$

PBS
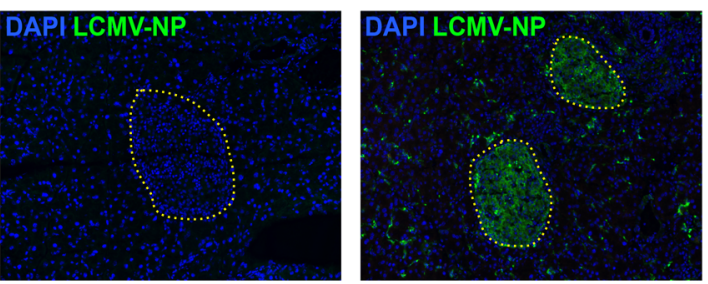

Day 15 post-LCMV

Day 53

post-LCMV

\section{DAPI LCMV-NP}

Figure 2. Clodronate liposome-induced depletion of macrophages prevents T1D disease. (A) Blood glucose levels of clodronate treated mice during a 54-day observation period. (B) Immunofluorescence inspection of (40x magnification) LCMV-GP $33-41^{-5 p e c i f i c ~ C D 8+~ P 14 ~ T ~ c e l l s ~ a n d ~ F 4 / 80+~}$ macrophages in the islets of clodronate or PBS liposome-treated mice at day 6 p.i. Yellow outlines represent islet boundaries, and yellow arrows show P14 CD8 ${ }^{+}$T cells. (C) Examination of P14 CD8 ${ }^{+} \mathrm{T}$ cells in the spleen and pancreatic lymph nodes (PLN) of clodronate liposome-treated mice at day 6 p.i. using flow cytometry. (D) Frequency of LCMV-GP $\mathrm{P}_{33-41}$ tetramer-positive and LCMV $_{396-404}$ tetramer-positive CD8 ${ }^{+} T$ cells in the spleens of clodronate treated mice at day 8 p.i. (E) Viral titers in the sera were measured by plaque assay over a 53 -day post-infection period. (F) Anti-LCMVNP staining (20x magnification) of pancreatic tissue from clodronate-treated mice at days 15 and 53 p.i. Yellow outlines depict islet boundaries. Flow cytometry data of P14 T cells represents at least 4 mice per group. Immunofluorescence analysis of islet-infiltrating T cells is an average of at least 8 islets per mouse and a total of 4 mice per group. Statistical significance was measured using 1-way ANOVA. Data are presented as average \pm SEM. ${ }^{*} P<0.05,{ }^{* * * *} P<0.0001$ 
A
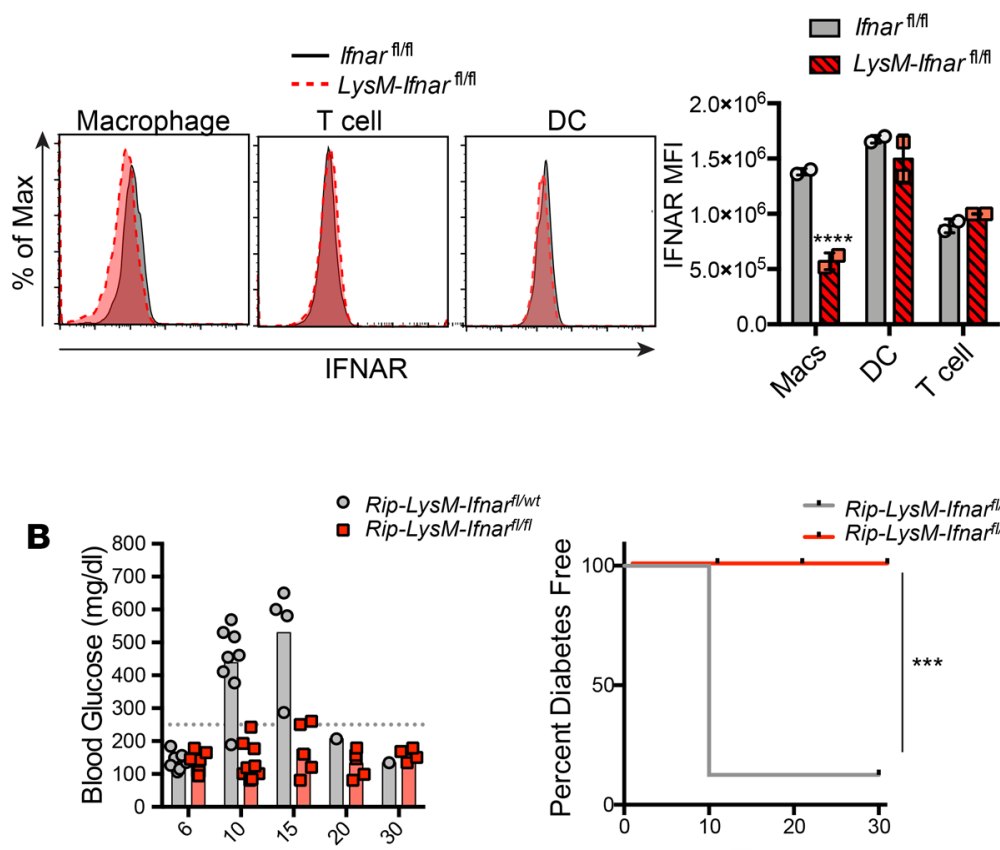

Day Post-LCMV

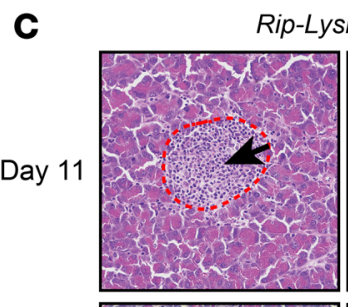

Rip-LysM-Ifnarfl/wt

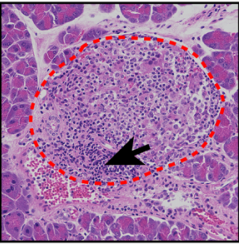

Day 30
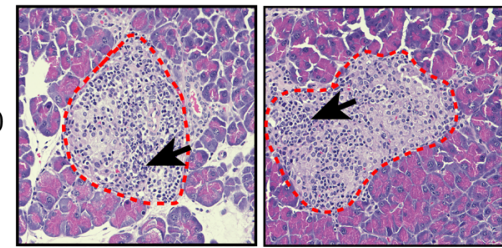

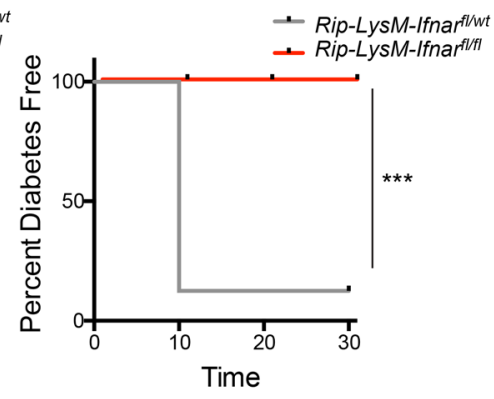

Rip-LysM-IfnarilfI

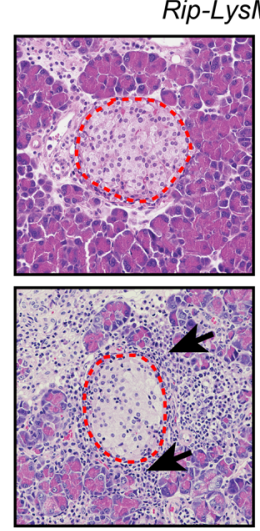

D
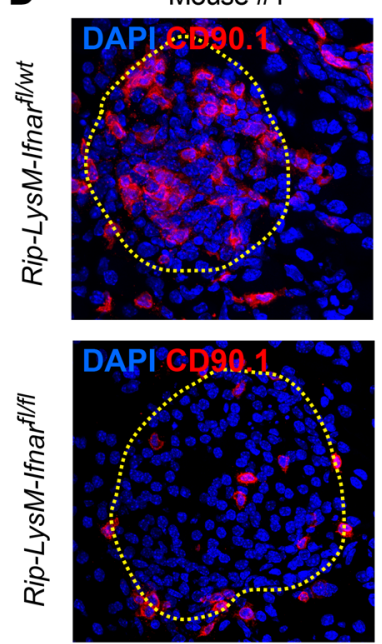

E

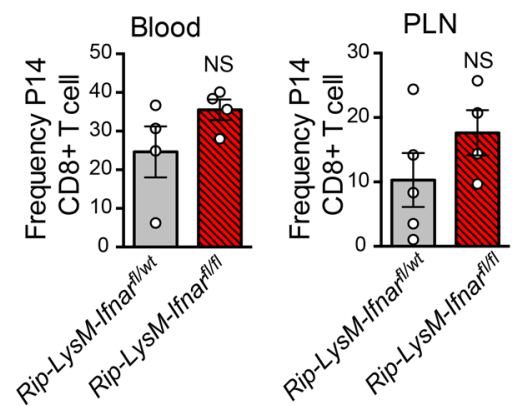

Figure 3. Genetic deletion of Ifnar from macrophages spares mice from T1D. (A) IFNAR expression levels (based on mean fluorescence intensity; MFI) on defined cellular subsets in the spleens of Rip-LysM-Ifnar ${ }^{\mathrm{fl} / \mathrm{fl}}$ mice compared with Ifnar ${ }^{\mathrm{fl} / \mathrm{fl}}$ mice. The following markers were used to gate splenic cell subsets: macrophages (CD11b+CD11 ${ }^{-}$F4/80+), T cells (CD3 ${ }^{+}$), and DCs (CD11b-CD11c ${ }^{+}$). Statistical significance was measured using 2-way ANOVA. (B) Rip-LysM-Ifnar fl/fl and Rip-LysM-Ifnar fl/wt mice were infected with LCMV-CI13, and BG levels were monitored over at 30-day period. Clinical diabetes was confirmed in mice that displayed BG levels significantly over $>250 \mathrm{mg} /$ dl. (C) H\&E staining (20x magnification) of pancreata from mice at day 11 p.i. and day 30 p.i. Red outlines depict islet boundaries. (D) Immunofluorescence detection (40x magnification) of P14 CD8 ${ }^{+}$T cells expressing the congenic surface marker CD90.1 in the pancreata of Rip-LysM-Ifnar ${ }^{\mathrm{fl} / \mathrm{fl}}$ and Rip-LysM-Ifnar ${ }^{\mathrm{fl} / \mathrm{wt}}$ at day 10 p.i. Yellow outlines depict islet boundaries. (E) Frequencies of P14 CD8 ${ }^{+} \mathrm{T}$ cells in the blood and PLN at day 10 p.i. IFNAR expression levels in the spleen are derived from 2 mice per group. Representative immunofluorescence images of P14 CD8 ${ }^{+}$T cells are derived from 4 mice per group. Black arrows in C represent areas of significant lymphoid accumulation. Statistical significant of T1D disease incidence was measured using a log-rank (Mantel-Cox) test. Data presented as average $\pm \mathrm{SEM}$. ${ }^{* *} P<0.001,{ }^{* * * *} P<0.0001$.

blood or PLNs of these mice, indicating that loss of IFNAR signaling in macrophages did not affect the expansion of P14 cells (Figure 3E).

Loss of Ifnar from macrophages enhances spread of LCMV. The inflammation observed within the pancreata but not in the islets of Rip-LysM-Ifnar ${ }^{\mathrm{f} / \mathrm{fl}}$ mice was likely due to immune-mediated injury of acinar cells, as the nucleoprotein (NP) antigen of LCMV was detected throughout acinus cells and within islets of these mice at day 11 p.i. (Figure 4A). Moreover, loss of Ifnar in Rip-LysM-Ifnar ${ }^{\mathrm{f} / \mathrm{fl}}$ mice resulted in increased LCMV titers in the serum of all infected mice at day 6 and day 10 p.i. but fell below the limit of detection in 3 of 4 Rip-LysM-Ifnar ${ }^{\mathrm{l} / \mathrm{fl}}$ mice by 30 p.i. (Figure 4B). Within the spleen, pancreas, kidney, 
A

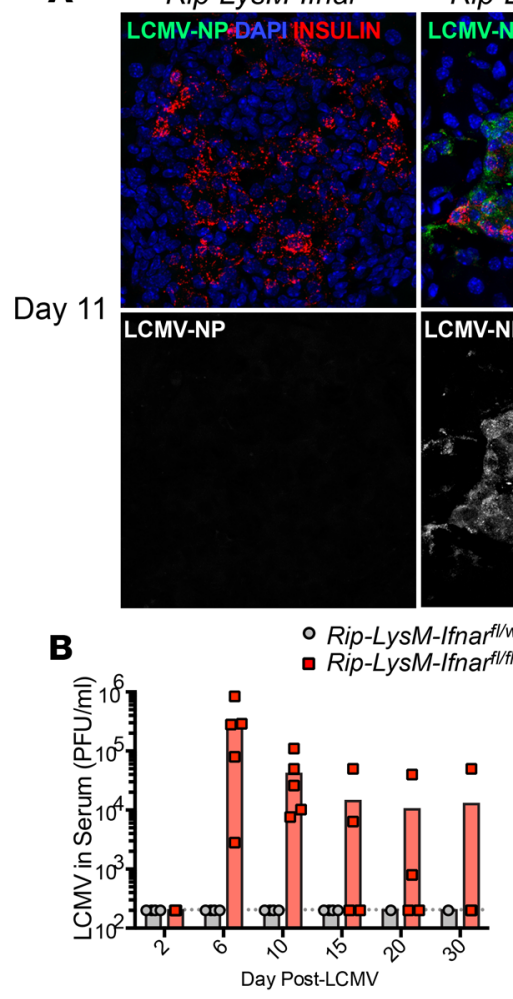

D

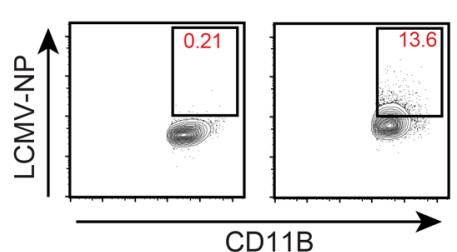

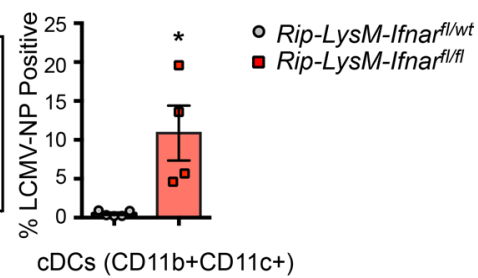
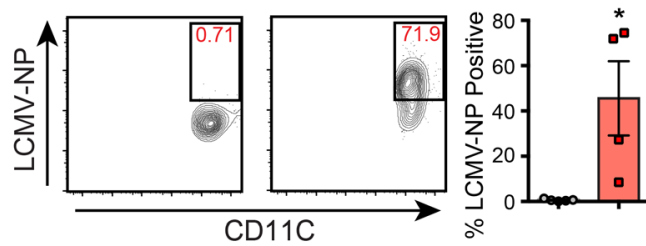

- Rip-LysM-Ifnarilwt - Rip-LysM-Ifnarififl

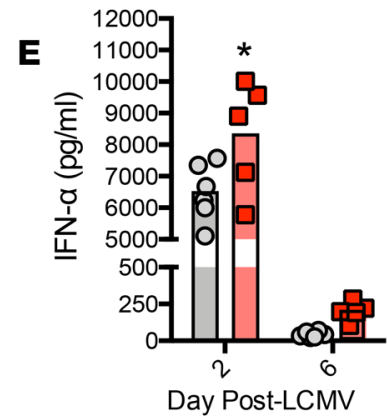

Figure 4. Loss of IFNAR signaling in macrophages results in systemic spread of LCMV. (A) Immunofluorescence analysis (40x magnification) of LCMV-NP antigen in pancreas tissue of Rip-LysM-Ifnar ${ }^{\text {fl/fl }}$ mice. (B and C) LCMV titers were recorded in the serum (B) and spleen, pancreas, kidney and liver (C) at day 11 p.i. by viral plaque assay. (D) Detection of the nucleoprotein (NP) of LCMV in macrophages (F4/80+CD11 ${ }^{+}$) and conventional dendritic cells (cDCs, CD11b+CD11c ${ }^{+}$in the spleens at day 11 p.i. (E) IFN- $\alpha$ protein levels were measured in the serum of Rip-LysM-Ifnar ${ }^{\mathrm{fl} / f \mathrm{l}}$ and Rip-LysM-Ifnar ${ }^{\mathrm{fl} / \mathrm{wt}}$ mice at days 2 and 6 p.i. Statistical significance was measured using an unpaired 2-tailed Student $t$ test or 1 -way ANOVA analysis. Data presented as average \pm SEM. ${ }^{*} P<0.05$.

and liver, infectious virus was significantly increased in Rip-LysM-Ifnar ${ }^{\mathrm{f} / \mathrm{fl}}$ mice compared with controls at day 11 p.i. (Figure 4C). Furthermore, elevated levels of LCMV-NP were detected in macrophages $\left(\mathrm{CD} 11 \mathrm{~b}^{+} \mathrm{F} 4 / 80^{+} \mathrm{CD} 11 \mathrm{c}^{-}\right)$and conventional DCs (cDCs, CD $\left.11 \mathrm{~b}^{+} \mathrm{CD} 11 \mathrm{c}^{\mathrm{hi}}\right)$ in the spleen by flow cytometry at day 11 p.i. (Figure 4D). The increase in viral titers was not likely caused by a lack of production of IFN-I, since levels of IFN- $\alpha$ and IFN- $\beta$ were similar to Rip-LysM-Ifnar ${ }^{\mathrm{fl} / \mathrm{wt}}$ control mice (Figure $4 \mathrm{E}$ ).

Although a similar frequency of LCMV-GP ${ }_{33-41}$-specific $\mathrm{CD}^{+} \mathrm{T}$ cells was observed in the spleens and PLNs of Rip-LysM-Ifnar ${ }^{\mathrm{f} / \mathrm{fl}}$ mice (Figure 5A), there was a detectable reduction of expression of the activation marker KLRG1 and increased expression of the inhibitory receptor PD-1 on the surface of LCMV-GP $_{33-41}$ tetramer-positive CD8 ${ }^{+} \mathrm{T}$ cells, suggesting partial exhaustion of these cells (Figure $5 \mathrm{~B}$ ). This finding was further supported by the observation that GP-specific CD8 ${ }^{+}$cells in the spleens of Rip-LysM-Ifnar ${ }^{\mathrm{f} / \mathrm{fl}}$ mice expressed significantly lower levels of IFN- $\gamma$ and TNF- $\alpha$ following restimulation with the LCMV-GP ${ }_{33-41}$-specific peptide at day 11 p.i. (Figure $5 \mathrm{C}$ ). We also examined the ex vivo killing capacity of LCMV-GP ${ }_{33-41}$-specific CTLs to lyse splenocytes loaded with the LCMV-GP ${ }_{33-41}\left(\mathrm{H}-2^{\mathrm{b}}\right)$ peptide antigen. Splenocytes isolated from LysM-Ifnar ${ }^{\mathrm{A} / \mathrm{fl}}$ mice at day $10 \mathrm{p} . \mathrm{i}$. had a significant reduction in specific killing of LCMV-GP-loaded target cells compared with LysM-Ifnar ${ }^{\mathrm{wt} / \mathrm{wt}}$ control mice (Figure 5D). Importantly, neither group killed target cells loaded with nonspecific LCMV-NP ${ }_{118-126}\left(\mathrm{H}-2^{\mathrm{d}}\right)$ peptide antigen (Figure 5D). Together, these results show that loss of Ifnar in macrophages resulted in a diminished LCMV-GP ${ }_{33-41}$-specific $\mathrm{CD}^{+} \mathrm{T}$ cell effector response that likely impacts the capacity of these cells to target and destroy $\beta$ cells of the islets.

\section{Discussion}

Our results highlight an important association between IFN-I signaling in macrophages during the prediabetic stage in an experimental model of T1D and indicate the control that macrophages exert over the selective 
A

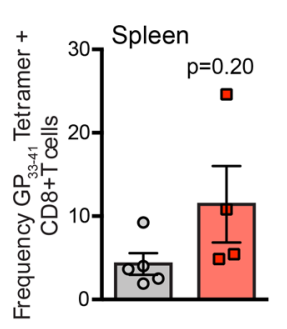

B

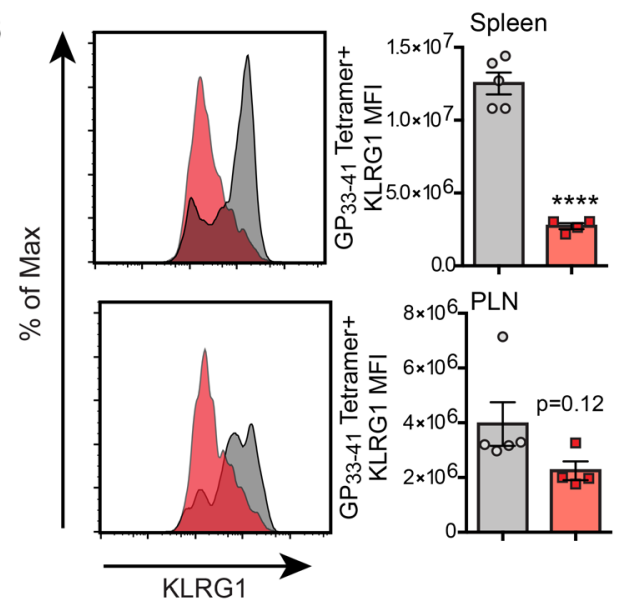

C
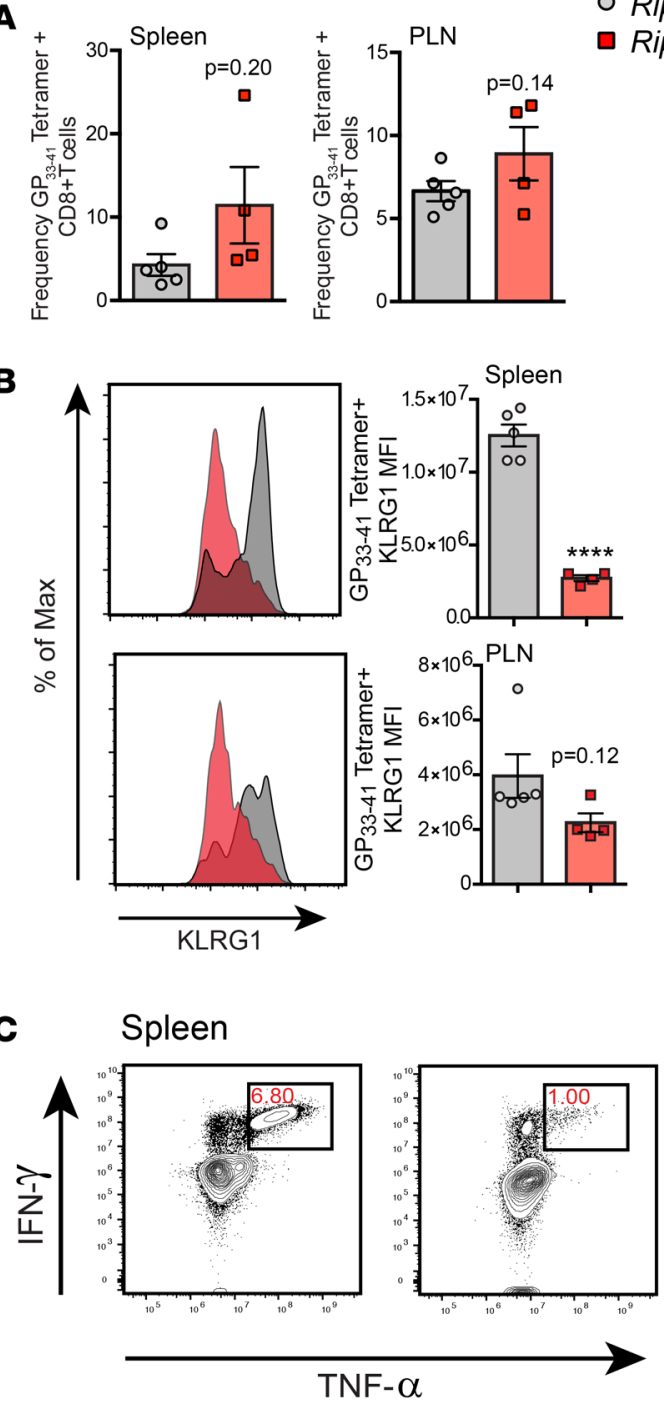

O Rip-LysM-Ifnarfl/wt

- Rip-LysM-Ifnar ${ }^{f / f f l}$
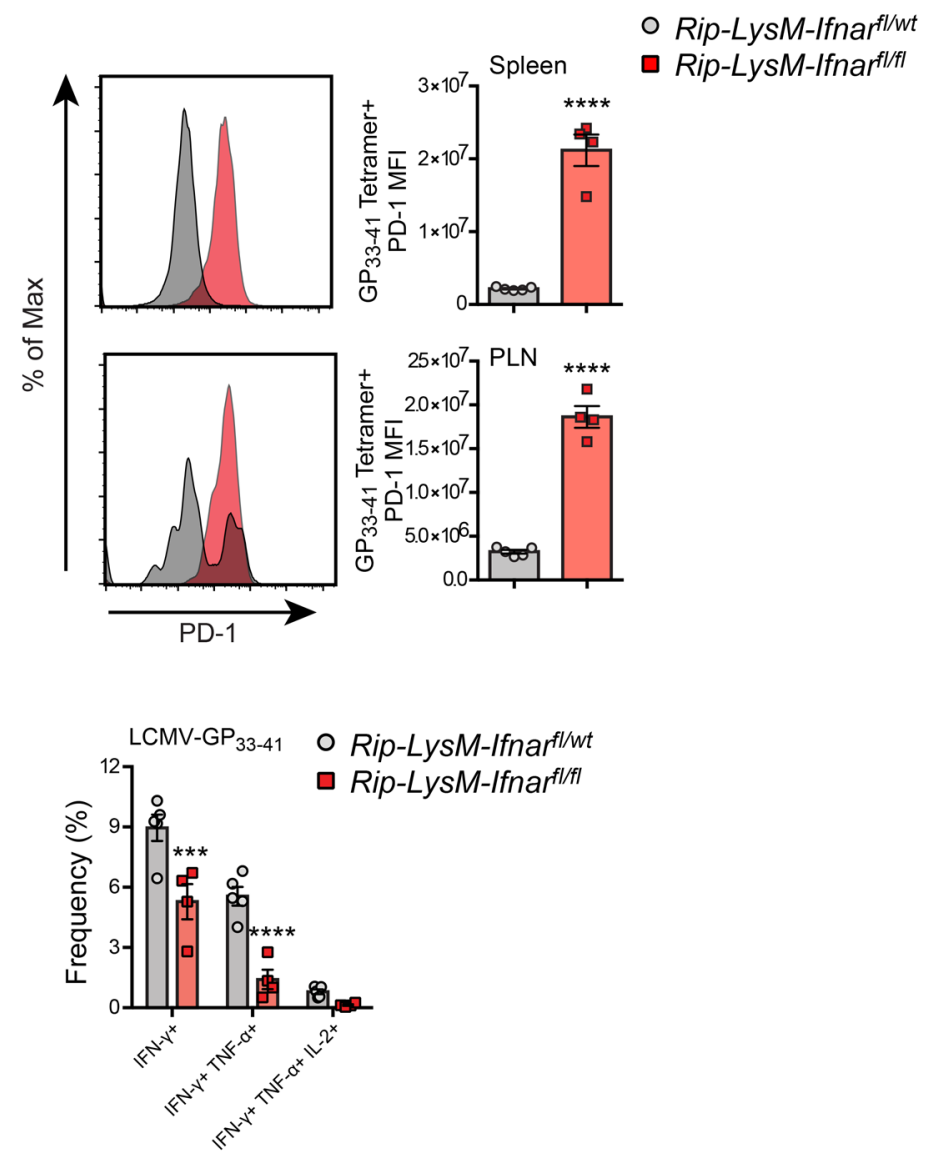

D
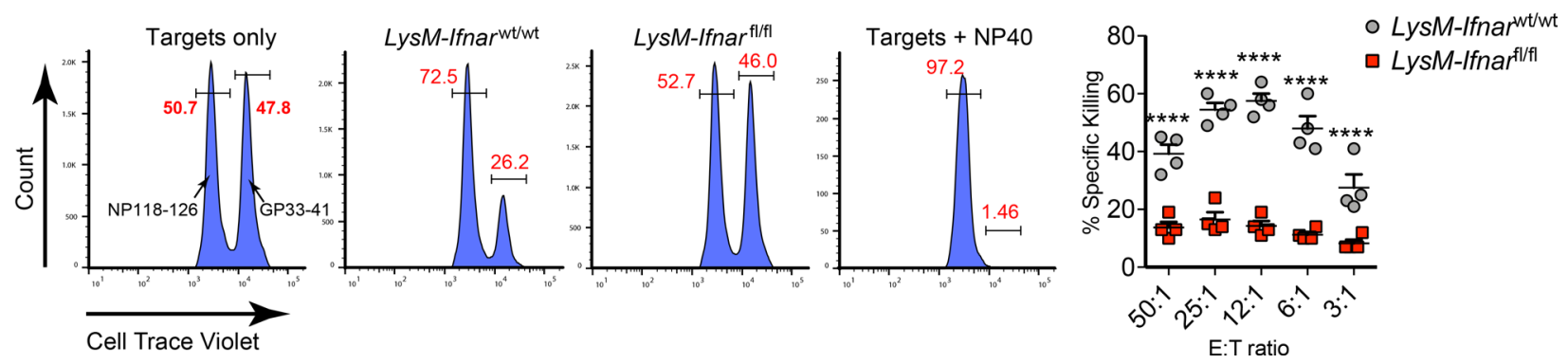

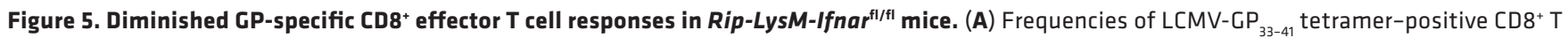

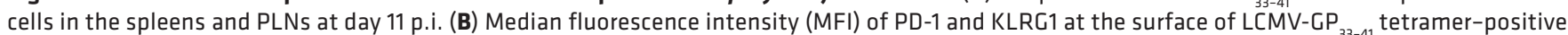
CD8 ${ }^{+}$T cells at day 11 p.i. (C) Detection of IFN- $\gamma$, TNF- $\alpha$, and IL-2 in CD8 ${ }^{+}$T cells following ex vivo restimulation of splencoytes from Rip-LysM-Ifnarl/fl mice with LCMV-GP 33-41 $_{1}$ peptide at day 11 p.i. (D) Specific lysis of target splenocytes loaded with CellTrace violet (CTV) and LCMV-CP ${ }_{33-41}\left(H-2^{b}, C^{2} V^{\text {hi }}\right.$ population) or $\mathrm{NP}_{118-126}\left(\mathrm{H}-2^{\mathrm{d}}, \mathrm{CTV}^{10}\right.$ population) peptides. Statistical significance was measured using an unpaired 2-tailed Student $t$ test, one-way ANOVA analysis or 2-way ANOVA analysis. Data presented as average \pm SEM. ${ }^{* * *} P<0.001,{ }^{* * *} P<0.0001$.

trafficking of autoimmune CTLs into the islets. Three potentially novel findings emerged from these studies. First, genetically ablating Ifnar in $\beta$ cells in the islets of Rip-Ins1-Ifnar ${ }^{\text {Il/ }}$ mice did not alter T1D disease progression following initiation of the autoimmune disease (LCMV infection). These results strongly suggest that sensitization of GP-specific $\mathrm{CD} 8^{+} \mathrm{T}$ cells to $\beta$ cells inside the islets occurs independently of IFNAR-induced 
gene expression inside $\beta$ cells and likely occurs outside the islets. However, it is possible that other proinflammatory factors, such as type II IFN- $\gamma$, play a role in altering the immunogenicity of $\beta$ cells, as IFN- $\gamma-\mathrm{KO}$ RipGP mice are resistant to T1D and display reduced islet MHC-I expression following infection with LCMV (35). Moreover, Rip-GP mice that overexpress IFN- $\gamma$ from $\beta$ cells break tolerance and spontaneously develop T1D without prior inoculation with LCMV (36). However, results with IFN- $\gamma$ appear different in nonobese diabetic (NOD) mice engineered to express dominant negative mutants of the IFN- $\gamma$ receptor. Such NOD mice display lower MHC-I expression from $\beta$ cells in the islets, while still showing normal T1D disease incidence (37). Both type I and type II IFNs display strong convergence in the IFN stimulate gene (ISG) signatures that they induce, and the prototypic T1D disease course observed in Rip-Ins1-Ifnar ${ }^{f / f l}$ mice suggests that the timing, magnitude, and temporal changes in IFN expression in the islets may be critical in potentiating T1D disease development in Rip-GP mice.

Second, clodronate-mediated depletion of macrophages or selective deletion of Ifnar in LysMexpressing cells aborted T1D disease. These findings support a critical role for IFN-I signaling in macrophages as an orchestrator of anti-LCMV immunity and an activator of autoaggressive CTLs targeting $\beta$ cells of the islets. Despite similar frequencies of GP-specific CD8 ${ }^{+} \mathrm{T}$ cells measured in the spleens and PLNs of Rip-LysM-Ifnar ${ }^{\mathrm{f} / \mathrm{fl}}$ mice, GP-specific CD8 ${ }^{+} \mathrm{T}$ cells showed reduced polyfunctional cytokine expression, altered cytotoxicity, and increased expression of PD-1, suggesting likely $\mathrm{T}$ cell dysfunction. Furthermore, the increase in viral load in Rip-LysM-Ifnar ${ }^{\mathrm{fl} / \mathrm{fl}}$ mice, previously shown to occur in mice depleted of macrophages or devoid of IFN-I signaling in macrophages $(30,38,39)$, was complementary to diminished $\mathrm{T}$ cell activity, since increased antigen abundance following LCMV infection directly influences $\mathrm{T}$ cell function (40).

Third, defects in the IFN-I pathway within macrophages resulted in widespread LCMV dissemination to the pancreata and in dramatic histological perturbations as a result of the influx of inflammatory cells. This result mimicked our previous observations using a blocking antibody to IFNAR (8) and further supports the role of IFNAR signaling as a protective signaling cascade to limit viral spread. Our prior studies primarily indicated IFN- $\alpha$, and not IFN- $\beta$, in retarding viral spread (41)

In conclusion, IFNAR signaling in macrophages plays a decisive role in T1D development. Studies in other experimental models, especially the nonviral spontaneous models, will be of value to understand the generality of our findings. Lastly, IFNAR signaling in macrophages also plays a role in regulating viral control during infection. Our future studies evaluate the role that various IFN- $\alpha$ species play in T1D with the purpose of developing a cocktail of specific IFN- $\alpha$ species-neutralizing antibodies or pharmacologic molecules that can limit T1D while preserving host-defense responses to microbial infections. We previously succeeded in such an approach using a single pharmacologic agonist molecule to sphingosine-1-phosphate receptor 1 to significantly reduce morbidity and mortality in ferrets and mice infected with the influenza virus (42-44). The mechanism included blocking approximately $85 \%-90 \%$ of the autocrine loop in IFN- 0 to prevent cytokine storm, while allowing sufficient remaining IFN- $\alpha$ to generate an adaptive immune response to limit and remove the virus infection (45-47).

In this regard, a group of humans susceptible to developing T1D due to mutations in AIRE (14) shown to generate self-reactive neutralizing antibodies to 5 IFN- $\alpha$ species (IFN- $\alpha 1$, IFN- $\alpha 2$, IFN- $\alpha 5$, IFN- $\alpha 8$, and IFN- $\alpha 14$ ) were protected from T1D, while - in contrast - those possessing antibodies to IFN- $\alpha$ but without significant neutralizing activity had a high incidence of T1D (14). Complementary to these findings (14), we noted that neutralizing at least 5 of the 13 IFN- $\alpha$ species of IFN-I with antibody in Rip-GP mice (IFN- $\alpha 1$, IFN- $\alpha 4$, IFN- $\alpha 5$, IFN- $\alpha 11$, IFN- $\alpha 13$ ) prevented the development of clinical T1D and anatomical lesions of T1D, while still preserving antiviral immunity (8). Two of the IFN- $\alpha$ species neutralized in humans and mice are similar (IFN- $\alpha 1$ and IFN- $\alpha 5$ ). It will be valuable to determine the binding profile of these antibodies to IFNAR and how they directly influence macrophage function to restrict the development of T1D.

\section{Methods}

Virus and mice. Seven- to 8-week-old H-2 $\mathrm{C}$-57BL/6 mice were used. Mice were bred and maintained in pathogen-free conditions in the animal facility at The Scripps Research Institute (TSRI). Generation and characterization of Rip-GP and P14 Tgs have previously been reported $(15,16,48)$. LCMV-Cl13 was grown and titered as previously described $(15,16,49)$. Stock viruses were titered to $4 \times 10^{7}$ to $5 \times 10^{7} \mathrm{PFU} /$ ml. Mice were injected with $2 \times 10^{5}$ PFU LCMV i.p. $(15,16,48)$. 
$B G$ monitoring. BG (mg/dl) was measured on blood extracted from the retro orbital plexus using a TRUEresult BG meter (Trividia Health).

Clodronate liposome preparation. Clodronate (dichloromethylene diphosphonate) encapsulated liposomes were prepared as previously described (29). Briefly, $4 \mathrm{mg}$ of cholesterol and $43 \mathrm{mg}$ of phosphatidylcholine (MiliporeSigma) reconstituted in chloroform were evaporated in an RN 10 rotary evaporator (IKA). The clodronate solution was prepared by dissolving $0.6 \mathrm{mg}$ of clodronate (MiliporeSigma) in $2.5 \mathrm{ml}$ of sterile DPBS (Thermo Fisher Scientific) and was used to disperse the lipic film under gentle rotation. The solution was sonicated and ultracentrifuged at $10,000 \mathrm{~g}$ for 1 hour at $4^{\circ} \mathrm{C}$. Pelleted clodronate-encapsulated liposomes were washed 3 times in sterile DPBS, ultracentrifuged at 10,000 $\mathrm{g}$ for 30 minutes at $4^{\circ} \mathrm{C}$, and resuspended in a final volume of $2.5 \mathrm{ml}$ in sterile DPBS. Liposomes were delivered into mice via i.v. injection $(200 \mu 1) 1$ day prior to LCMV-Cl13 infection and by i.p. injection 8 hours after LCMV-C113 infection. Clodronate solution was used within 48 hours after preparation.

Pancreatic islet isolation. Pancreata isolated from Rip-LCMV-GP mice were placed in $5 \mathrm{ml}$ cold RPMI. To dissociate tissue, $3 \mathrm{ml}$ of Collagenase $\mathrm{P}(1.2 \mathrm{U} / \mathrm{ml}$, MilliporeSigma) was injected directly into each pancreas using a $30-\mathrm{G}$ needle and digested at $37^{\circ} \mathrm{C}$ following addition of $7 \mathrm{ml}$ warm RPMI. After 30 minutes, Collagenase P solution was removed, and $10 \mathrm{ml}$ of ice-cold RPMI was added. Tubes were shaken vigorously for 1 minute to break apart tissue, which was passed through a wide-mesh sieve to remove nondissociated debris. Following several washing steps, RPMI media was removed, and 10 $\mathrm{ml}$ of prewarmed Ficoll-Paque Plus (GE Healthcare) was added. A 5-ml RPMI overlay was added to Ficoll, and cells were spun at $2000 \mathrm{rpm}$ for 13 minutes at room temperature to separate islets from exocrine cells. After the spin, islets were isolated at the Ficoll/RPMI interface using a plastic Pasteur pipet, spun in cold RPMI media at $1000 \mathrm{rpm}$ for 5 minutes, and added onto an inverted $70-\mu \mathrm{M}$ filter to further remove nonislet debris; they were then placed into a petri dish with RPMI and 10\% FBS (Atlanta Biologics). Islets were then cultured in RPMI supplemented with $10 \% \mathrm{FBS}, 1 \%$ penicillin/streptomycin (Thermo Fisher Scientific), and 1\% L-glutamine (Thermo Fisher Scientific).

Gene expression analysis. Total cDNA from islets was generated via SuperScript III (Thermo Fisher Scientific) following extraction of RNA using RNAqueous Micro RNA isolation kit (Thermo Fisher Scientific). To determine relative expression of IFN-I-stimulated genes in islets following 24-hour treatment with IFN- $\beta$ (100 units/ml, PBL Assay Science), real-time SYBR Green analysis was performed using mouse primers to $\beta$-actin (forward, 5'-GGCCCAGAGCAAGAGAGGTAT-3'; reverse, 5'-ACGCACGATTTCCCTCTCAGC-3'), pan IFN- $\alpha$ (forward, 5'-CCCTCCTAGACTCATTCTGCA-3'; reverse, 5'-AGGCACAGGGGCTGTGTTTC-3'), Mx1 (forward， 5'-GACCATAGGGGTCTTGACCAA-3'; reverse, 5'-AGACTTGCTCTTTCTGAAAAGCC-3'), Ifit1 (forward, 5'-CTGAGATGTCACTTCACATGGAA-3'; reverse, 5'-GTGCATCCCCAATGGGTTCT-3'), Ifit2 (forward, 5'-AGTACAACGAGTAAGGAGTCACT-3'; reverse, 5'-AGGCCAGTATGTTGCACATGG-3'), Stat1 (forward, 5'-GCTGCCTATGATGTCTCGTTT-3'; reverse, 5'-TGCTTTTCCGTATGTTGTGCT-3'), and Oasl2 (forward, 5'-TTGTGCGGAGGATCAGGTACT-3'; reverse, 5'-TGATGGTGTCGCAGTCTTTGA-3') using a Bio-Rad CFX96 Touch real-time detection system. To calculate fold change of selected genes in IFN- $\beta$-treated islets, mRNA expression was first normalized $\beta$-actin to generate a $\triangle \mathrm{Ct}$ value and then to PBS-treated islets to generate a $\Delta \Delta \mathrm{Ct}$ value. Fold change in expression was calculated using the standard $2^{-\Delta \Delta C t}$ equation.

Histology and IF analysis. Pancreata were removed, fixed in zinc formalin (10\%), cut on a microtome, and stained with H\&E. For IF, mice were first perfused with $4 \%$ paraformaldehyde (PFA). Pancreata were then removed and placed overnight at $4^{\circ} \mathrm{C}$ in PFA. Tissue was transferred to a $30 \%$ sucrose solution for 3 days prior to cutting at $10 \mu \mathrm{M}$ on a cryomicrotome. For antibody staining, slides were dessicated for 1 hour at room temperature, washed in PBS, and blocked with 5\% normal goat serum. Primary antibody stains were carried out in PBS supplemented with 1\% BSA (Gemini Bio Products) and 0.3\% Triton X-100 (for intracellular antigens; MilliporeSigma) using FITC anti-CD90.1 (1:200, BioLegend), rabbit anti-FITC (1:200, Thermo Fisher Scientific), rat anti-mouse F4/80 (Bio-Rad, clone CL:A3-1, catalog MCA497), guinea pig anti-insulin (Thermo Fisher Scientific, polyclonal, catalog PA1-26938), and rat anti-LCMV-NP FITC. Fluorescently conjugated Alexa Fluor (Thermo Fisher Scientific) secondary antibodies were diluted at 1:1000 and mounted with DAPI fluoromount-G (Southern Biotech).

Flow cytometry. Spleens were digested using a mixture of collogenase/DNase prior to homogenation on a $100-\mu \mathrm{M}$ filter using the end of a syringe. RBCs were lysed for 3 minutes in $1 \times \mathrm{RBC}$ lysis buffer. Rat anti-mouse IFNAR (Leinco, clone MAR1-5A3, catalog I-401), -F4/80 (BioLegend, clone BM8), -CD11b 
(BioLegend, clone M1/70), -CD11c (BioLegend, clone N418), -CD45 (BioLegend, clone 30-F11), CD4 (BioLegend, clone RM4-5), -CD8 (BioLegend, clone53-6.7), -TNF- $\alpha$ (BioLegend, clone MP6-XT22), IL-2 (BioLegend, clone JES6-5H4), and rat anti-mouse IFN- $\gamma$ (BD Biosciences, clone XMG1.2) were utilized at a 1:100 dilution.

Ex vivo peptide restimulation assay. Splenocytes were seeded onto round-bottom 96-well plates at $1 \times 10^{6}$ cells/well in complete media (10\% FBS, L-glutamine, penicillin/streptomycin, nonessential amino acids (NEAA), sodium pyruvate, HEPES, $\beta$-mercaptoethanol [BME]) supplemented with LCMV-specific peptides $\left(\mathrm{GP}_{33-41}\right.$ and $\left.\mathrm{GP}_{276-286}\right)$. After a 1-hour incubation, Brefeldin A (MilliporeSigma) was added at a 1:500 dilution and cells were incubated for 5 hours at $37^{\circ} \mathrm{C}$. Surface antigens were stained for 30 minutes on ice; cells fixed and permeabilized using Cytofix/Cytoperm (BD Pharmingen) and stained for intracellular proteins including IFN- $\gamma$ and TNF- $\alpha$.

CTL assay. Splenocytes from naive C57BL/ 6 mice were resuspended at $3.5 \times 10^{8}$ cells $/ \mathrm{ml}$ in $100 \mu 1$ PBS and rapidly mixed with $900 \mu 1$ of CellTrace Violet (CTV, Thermo Fisher Scientific) at 1:100 (CTV ${ }^{\text {hi }}$ ) or 1:800 $\left(\mathrm{CTV}^{10}\right)$ dilutions. Cells incubated for 20 minutes in a $37^{\circ} \mathrm{C}$ water bath and then washed with complete RPMI 1640 medium prior to centrifugation at $500 \mathrm{~g}$. The $\mathrm{CTV}^{\text {hi }}$ cell pellet was resuspended in a $1-\mathrm{ml}$ RPMI 1640 solution containing $2 \mu \mathrm{M}$ LCMV-GP ${ }_{33-41}$ peptide, while the CTV ${ }^{\text {lo }}$ cell pellet was resuspended in $2 \mu \mathrm{M}$ LCMV-NP ${ }_{118-126}$ peptide. Both groups were incubated for 30 minutes at $37^{\circ} \mathrm{C}$. The $\mathrm{CTV}^{\text {hi }}(\mathrm{GP} 33)$ and $\mathrm{CTV}^{\mathrm{lo}}(\mathrm{NP} 118)$ cell populations were then mixed at a 1:1 ratio and adjusted to $2 \times 10^{6} \mathrm{cells} / \mathrm{ml}$ prior to seeding $100 \mu \mathrm{l}$ of target cells into 96-well round-bottom plates. Purified splenocytes from LCMV-infected LysM-Ifnar ${ }^{\mathrm{wt} / \mathrm{wt}}$ and LysM-Ifnar ${ }^{\mathrm{fl} / \mathrm{fl}}$ mice were plated at effector/target ratios (E:T ratios) of 25:1, 12:1, 6:1, 3:1, and $0: 1$ in 96-well round-bottom plates. A negative control was produced by incubating LCMVGP-loaded CTV ${ }^{\text {hi }}$ cells with NP40 for 2 minutes at room temperature and then mixed 1:1 with untreated $\mathrm{CTV}^{10}$ cells. Plates were placed in a $37^{\circ} \mathrm{C}+5 \% \mathrm{CO}_{2}$ incubator for 5 hours. After the incubation, 7-AAD (BD Biosciences) was added to each well at a 1:100 dilution, and plates were run on a Bio-Rad ZE5 flow cytometer. The following formula was used to calculate the percentage of specific killing: $\left(1-\left[\left(\% \mathrm{CTV}^{\mathrm{hi}}\right.\right.\right.$ in effector sample $/ \% \mathrm{CTV}^{\mathrm{lo}}$ in effector sample $) /\left(\% \mathrm{CTV}^{\text {hi }}\right.$ of naive group $/ \% \mathrm{CTV}^{\mathrm{lo}}$ of naive group $\left.\left.)\right]\right) \times 100$.

Statistics. Two means were compared using a 2-tailed unpaired Student's $t$ test. Multiple comparisons were performed using 1-way ANOVA followed by Tukey's multiple comparison test or 2-way ANOVA followed by Sidak's multiple comparison test. Statistical significance is denoted as follows: ${ }^{*} P<0.05,{ }^{*} P<$ $0.01,{ }^{* *} P<0.001,{ }^{* * * *} P<0.0001$. GraphPad Prism 6 was used for all statistical analysis.

Study Approval. All procedures involving mice were reviewed and approved with TSRI Animal Research Committee.

\section{Author contributions}

BSM, SL, and MBAO designed research; BSM, SL, and BCW performed research; BSM, SL, and MBAO analyzed data; and BSM, SL, and MBAO wrote the paper.

\section{Acknowledgments}

This work was supported by NIH grant AI099699 (MBAO), Jeanette Bertea Hennings Foundation fellowship award (BSM), and NIH T32 training grant 5T32AI007244-33 (BSM).

Address correspondence to: Michael B.A. Oldstone, Viral-Immunobiology Laboratory, Department of Immunology \& Microbiology, The Scripps Research Institute, 10550 North Torrey Pines Road, La Jolla, CA 92037, USA. Phone: 858.784.8054; Email: mbaobo@scripps.edu.

\footnotetext{
1. Foulis AK, Farquharson MA, Meager A. Immunoreactive alpha-interferon in insulin-secreting beta cells in type 1 diabetes mellitus. Lancet. 1987;2(8573):1423-1427.

2. Huang X, et al. Interferon expression in the pancreases of patients with type I diabetes. Diabetes. 1995;44(6):658-664.

3. Pelegrin M, et al. Evidence from transgenic mice that interferon-beta may be involved in the onset of diabetes mellitus. $J$ Biol Chem. 1998;273(20):12332-12340.

4. Alba A, et al. IFN beta accelerates autoimmune type 1 diabetes in nonobese diabetic mice and breaks the tolerance to beta cells in nondiabetes-prone mice. J Immunol. 2004;173(11):6667-6675.

5. Stewart TA. Neutralizing interferon alpha as a therapeutic approach to autoimmune diseases. Cytokine Growth Factor Rev. 2003;14(2):139-154

6. Li Q, Xu B, Michie SA, Rubins KH, Schreriber RD, McDevitt HO. Interferon-alpha initiates type 1 diabetes in nonobese diabetic
} 
mice. Proc Natl Acad Sci USA. 2008;105(34):12439-12444.

7. Unanue ER, Ferris ST, Carrero JA. The role of islet antigen presenting cells and the presentation of insulin in the initiation of autoimmune diabetes in the NOD mouse. Immunol Rev. 2016;272(1):183-201.

8. Marro BS, Ware BC, Zak J, de la Torre JC, Rosen H, Oldstone MB. Progression of type 1 diabetes from the prediabetic stage is controlled by interferon- $\alpha$ signaling. Proc Natl Acad Sci USA. 2017;114(14):3708-3713.

9. Lang KS, et al. Toll-like receptor engagement converts T-cell autoreactivity into overt autoimmune disease. Nat Med. 2005;11(2):138-145

10. Akiyama R, Ågren J. Magnitude and timing of leaf damage affect seed production in a natural population of Arabidopsis thaliana (Brassicaceae). PLoS ONE. 2012;7(1):e30015.

11. Carrero JA, Calderon B, Towfic F, Artyomov MN, Unanue ER. Defining the transcriptional and cellular landscape of type 1 diabetes in the NOD mouse. PLOS ONE. 2013;8(3):e59701.

12. Ferreira RC, et al. A type I interferon transcriptional signature precedes autoimmunity in children genetically at risk for type 1 diabetes. Diabetes. 2014;63(7):2538-2550.

13. Kallionpää H, et al. Innate immune activity is detected prior to seroconversion in children with HLA-conferred type 1 diabetes susceptibility. Diabetes. 2014;63(7):2402-2414.

14. Meyer S, et al. AIRE-Deficient Patients Harbor Unique High-Affinity Disease-Ameliorating Autoantibodies. Cell. 2016;166(3):582-595.

15. Oldstone MB, Nerenberg M, Southern P, Price J, Lewicki H. Virus infection triggers insulin-dependent diabetes mellitus in a transgenic model: role of anti-self (virus) immune response. Cell. 1991;65(2):319-331.

16. von Herrath MG, Dockter J, Oldstone MB. How virus induces a rapid or slow onset insulin-dependent diabetes mellitus in a transgenic model. Immunity. 1994;1(3):231-242.

17. Oldstone MB. Molecular and cellular mechanisms, pathogenesis, and treatment of insulin-dependent diabetes obtained through study of a transgenic model of molecular mimicry. Curr Top Microbiol Immunol. 2005;296:65-87.

18. Montoya M, et al. Type I interferons produced by dendritic cells promote their phenotypic and functional activation. Blood. 2002;99(9):3263-3271

19. Bottazzo GF, Dean BM, McNally JM, MacKay EH, Swift PG, Gamble DR. In situ characterization of autoimmune phenomena and expression of HLA molecules in the pancreas in diabetic insulitis. N Engl J Med. 1985;313(6):353-360.

20. Marroqui L, et al. Interferon- $\alpha$ mediates human beta cell HLA class I overexpression, endoplasmic reticulum stress and apoptosis, three hallmarks of early human type 1 diabetes. Diabetologia. 2017;60(4):656-667.

21. Coppieters KT, et al. Demonstration of islet-autoreactive CD8 T cells in insulitic lesions from recent onset and long-term type 1 diabetes patients. J Exp Med. 2012;209(1):51-60.

22. Calderon B, et al. The pancreas anatomy conditions the origin and properties of resident macrophages. J Exp Med. 2015;212(10):1497-1512.

23. Ferris ST, Carrero JA, Mohan JF, Calderon B, Murphy KM, Unanue ER. A minor subset of Batf3-dependent antigen-presenting cells in islets of Langerhans is essential for the development of autoimmune diabetes. Immunity. 2014;41(4):657-669.

24. Ferris ST, et al. The islet-resident macrophage is in an inflammatory state and senses microbial products in blood. J Exp Med. 2017;214(8):2369-2385.

25. Westwell-Roper CY, Ehses JA, Verchere CB. Resident macrophages mediate islet amyloid polypeptide-induced islet IL-1 $\beta$ production and $\beta$-cell dysfunction. Diabetes. 2014;63(5):1698-1711.

26. Vomund AN, et al. Beta cells transfer vesicles containing insulin to phagocytes for presentation to T cells. Proc Natl Acad Sci USA. 2015;112(40):E5496-E5502.

27. Zinselmeyer BH, Vomund AN, Saunders BT, Johnson MW, Carrero JA, Unanue ER. The resident macrophages in murine pancreatic islets are constantly probing their local environment, capturing beta cell granules and blood particles. Diabetologia. 2018;61(6):1374-1383.

28. Carrero JA, et al. Resident macrophages of pancreatic islets have a seminal role in the initiation of autoimmune diabetes of NOD mice. Proc Natl Acad Sci USA. 2017;114(48):E10418-E10427.

29. Van Rooijen N, Sanders A. Liposome mediated depletion of macrophages: mechanism of action, preparation of liposomes and applications. J Immunol Methods. 1994;174(1-2):83-93.

30. Seiler P, Aichele P, Odermatt B, Hengartner H, Zinkernagel RM, Schwendener RA. Crucial role of marginal zone macrophages and marginal zone metallophils in the clearance of lymphocytic choriomeningitis virus infection. Eur J Immunol. 1997;27(10):2626-2633.

31. Faust N, Varas F, Kelly LM, Heck S, Graf T. Insertion of enhanced green fluorescent protein into the lysozyme gene creates mice with green fluorescent granulocytes and macrophages. Blood. 2000;96(2):719-726.

32. Diamond MS, et al. Type I interferon is selectively required by dendritic cells for immune rejection of tumors. $J$ Exp Med. 2011;208(10):1989-2003.

33. Prinz M, et al. Distinct and nonredundant in vivo functions of IFNAR on myeloid cells limit autoimmunity in the central nervous system. Immunity. 2008;28(5):675-686.

34. Clausen BE, Burkhardt C, Reith W, Renkawitz R, Förster I. Conditional gene targeting in macrophages and granulocytes using LysMcre mice. Transgenic Res. 1999;8(4):265-277.

35. von Herrath MG, Oldstone MB. Interferon-gamma is essential for destruction of beta cells and development of insulin-dependent diabetes mellitus. J Exp Med. 1997;185(3):531-539.

36. Lee MS, von Herrath M, Reiser H, Oldstone MB, Sarvetnick N. Sensitization to self (virus) antigen by in situ expression of murine interferon-gamma. J Clin Invest. 1995;95(2):486-492.

37. Thomas HE, Parker JL, Schreiber RD, Kay TW. IFN-gamma action on pancreatic beta cells causes class I MHC upregulation but not diabetes. J Clin Invest. 1998;102(6):1249-1257.

38. Lang PA, et al. Tissue macrophages suppress viral replication and prevent severe immunopathology in an interferon-I-dependent manner in mice. Hepatology. 2010;52(1):25-32.

39. Louten J, van Rooijen N, Biron CA. Type 1 IFN deficiency in the absence of normal splenic architecture during lymphocytic 
choriomeningitis virus infection. J Immunol. 2006;177(5):3266-3272.

40. Barber DL, et al. Restoring function in exhausted CD8 T cells during chronic viral infection. Nature. 2006;439(7077):682-687.

41. Ng CT, et al. Blockade of interferon Beta, but not interferon alpha, signaling controls persistent viral infection. Cell Host Microbe. 2015;17(5):653-661.

42. Walsh KB, et al. Suppression of cytokine storm with a sphingosine analog provides protection against pathogenic influenza virus. Proc Natl Acad Sci USA. 2011;108(29):12018-12023.

43. Oldstone $\mathrm{MB}$, Rosen $\mathrm{H}$. Cytokine storm plays a direct role in the morbidity and mortality from influenza virus infection and is chemically treatable with a single sphingosine-1-phosphate agonist molecule. Curr Top Microbiol Immunol. 2014;378:129-147.

44. Teijaro JR, et al. Protection of ferrets from pulmonary injury due to H1N1 2009 influenza virus infection: immunopathology tractable by sphingosine-1-phosphate 1 receptor agonist therapy. Virology. 2014;452-453:152-157.

45. Walsh KB, et al. Animal model of respiratory syncytial virus: CD8+ T cells cause a cytokine storm that is chemically tractable by sphingosine-1-phosphate 1 receptor agonist therapy. J Virol. 2014;88(11):6281-6293.

46. Teijaro JR, Walsh KB, Rice S, Rosen H, Oldstone MB. Mapping the innate signaling cascade essential for cytokine storm during influenza virus infection. Proc Natl Acad Sci USA. 2014;111(10):3799-3804.

47. Teijaro JR, et al. S1PR1-mediated IFNAR1 degradation modulates plasmacytoid dendritic cell interferon- $\alpha$ autoamplification Proc Natl Acad Sci USA. 2016;113(5):1351-1356.

48. Oldstone MB, Edelmann KH, McGavern DB, Cruite JT, Welch MJ. Molecular anatomy and number of antigen specific CD8 T cells required to cause type 1 diabetes. PLoS Pathog. 2012;8(11):e1003044.

49. Lewicki H, et al. CTL escape viral variants. I. Generation and molecular characterization. Virology. 1995;210(1):29-40. 